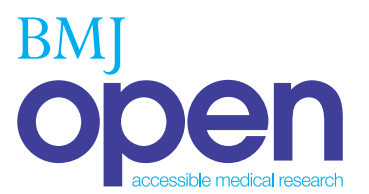

\title{
Health literacy, health empowerment and health information search in the field of MMR vaccination: a cross-sectional study protocol
}

\author{
Nicola Diviani, ${ }^{1}$ Anne-Linda Camerini, ${ }^{1}$ Danuta Reinholz, ${ }^{2}$ Alessandra Galfetti, ${ }^{2}$ \\ Peter J Schulz ${ }^{1}$
}

To cite: Diviani N, Camerini A-L, Reinholz D, et al. Health literacy, health empowerment and health information search in the field of MMR vaccination: a cross-sectional study protocol. BMJ Open 2012;2:e002162.

doi:10.1136/bmjopen-2012002162

- Prepublication history for this paper are available online. To view these files please visit the journal online (http://dx.doi.org/10.1136/ bmjopen-2012-002162).

Received 26 September 2012 Accepted 19 October 2012

This final article is available for use under the terms of the Creative Commons Attribution Non-Commercial 2.0 Licence; see http://bmjopen.bmj.com

\section{ABSTRACT}

Objectives: Although public health offices have a detailed record of the vaccination coverage among adolescents in Switzerland, little is known about the factors that determine the decisions of parents to get their children vaccinated. Based on Schulz \&

Nakamoto's Extended Health Empowerment Model, the present study aims at surveying parents of adolescents in Ticino (Switzerland) to get insights into the role of health literacy, health empowerment, information search behaviour and potential confounding variables that influence whether adolescents are not at all vaccinated, undervaccinated or fully covered against measles, mumps and rubella (MMR).

Methods and analysis: A survey including concepts of the Extended Health Empowerment Model will be administered to all families with adolescents attending the third year of middle school in Ticino. Subsequently, survey responses will be matched with actual data on MMR vaccination coverage of adolescents collected from the Cantonal Office of Public Health in Ticino.

Discussion: The results of this study will allow one to draw more comprehensive conclusions about the factors that play a role in parents' decisions regarding the vaccination of their children. At the same time, the study will provide useful insights on which are the main issues to be considered when addressing parents (on an interpersonal as well as a mass communication level) regarding the vaccination of their children.

\section{INTRODUCTION}

Measles is a highly contagious, acute viral disease that can lead to serious complications and death ${ }^{1}$ but the disease can be largely prevented by vaccination. In 2007, worldwide coverage of the first dose of measles vaccine reached 82\%; between 2000 and 2007, the estimated number of deaths from measles dropped from 750000 to 197000 . However, measles remains an important cause of death and disability in countries with limited health infrastructure. In countries where

\section{ARTICLE SUMMARY}

Article focus

- A protocol for a cross-sectional survey of parents of adolescents in Ticino (Switzerland) to examine the impact of health literacy, health empowerment, health information search, attitudes and beliefs on parents' decision to vaccinate their children against measles, mumps and rubella (MMR).

- Detailed description of the questionnaire used in the survey and how survey data will be matched with vaccination coverage data.

\section{Key messages}

- More evidence is needed for the intrapersonal and interpersonal factors explaining parents' decisions to vaccinate-or not to vaccinatetheir children against MMR.

- Results of the study will provide useful insights on the main issues that need to be addressed when dealing with parents regarding vaccinationrelated issues.

Strengths and limitations of this study

- The proposed study is one of the first to match parents' survey data with actual not self-reported data on the vaccination coverage against MMR of their children.

- MMR vaccination rates in Ticino are generally high and, therefore, there is a risk of low variance in the outcome measure.

vaccination has substantially reduced the incidence of measles, failure to maintain high coverage of childhood immunisation in all districts has resulted in a resurgence of the disease. The coverage targets depend on national goals for disease control. In countries aiming to reduce death rates from measles, immunisation coverage should be $\geq 90 \%$ at the national level and $\geq 80 \%$ in each district. Countries targeting at measles elimination should achieve $\geq 95 \%$ coverage with both doses in every district. ${ }^{2}$ 
In the Canton of Ticino (Italian-speaking Switzerland), although vaccination is promoted as a key prevention tool, it is not compulsory (see RL 6.1.2.1.1 Regolamento concernente le vaccinazioni contro le malattie trasmissibili (Regulation of vaccination against communicable diseases), February 2003). This is one of the reasons why vaccination coverage has not yet reached the levels required to extinguish measles in Switzerland. As a consequence, the confederation experienced several large measles outbreaks in the last two decades. For instance, 235 cases were reported in 1997 and 614 in 2003. ${ }^{3}$ Another outbreak was experienced between 2006 and 2009, with 4400 reported cases. ${ }^{4}$ More recently, between December 2010 and August 2011, 679 cases were reported. ${ }^{5}$ Most of the infected cases were undervaccinated or not at all vaccinated.

In order to be fully covered against measles, a person should have received a combined dosage for measles, mumps and rubella (MMR) by the age of 12 months and another by the age of 24. Data from a coverage study conducted in Switzerland between 2005 and 2007 showed that by the time adolescents complete secondary education, only $54 \%$ of them are fully vaccinated against measles, $94 \%$ receive at least one dosage and, therefore, are undervaccinated and $6 \%$ receive no vaccination against the disease. ${ }^{3}$ Since the trend for vaccination against measles is decreasing, the Swiss Federal Office of Public Health has developed a national strategy to eliminate measles before the end of $2015^{4}$ and has planned to launch a campaign in 2013 to raise parents' awareness of the risks of measles and the need for appropriate vaccination of their children. The present study, conducted in collaboration with the Cantonal Office of Public Health $(\mathrm{COPH})$ in Ticino, is part of the strategic axis Communication and prevention of the national strategy, and aims to: (1) collect measles' vaccination coverage data among middle-school students residing in the Canton of Ticino and (2) conduct a survey on the factors influencing parents' decisions and actions to get their children vaccinated or not.

\section{Theoretical background}

Vaccination is a preventive health behaviour that entails the immunisation of a healthy person against an infectious disease. As such, it can be considered a health behaviour. Health behaviours have been studied systematically and theories about their predictors and outcomes have been developed and tested. These theories concentrate on motivational aspects of health behaviour rooted in beliefs-for example, the Health Belief Model ${ }^{6}$ - selfefficacy and outcome expectations-for example, the Social Cognitive Theory ${ }^{7}{ }^{8}$-or attitudes and social norms-for example, the Theory of Planned Behaviour. ${ }^{9}$ Another approach focuses on informational aspects and the need for health education to promote constructive health behaviours. ${ }^{10}$ Both aspects are incorporated in the Health Empowerment Model ${ }^{11}$ that considers health literacy and psychological empowerment as two equally important predictors of health behaviour.

Health literacy stems from the general concept of literacy, which is the ability to read and write. ${ }^{12}$ Correspondingly, the Ad Hoc Committee on Health Literacy defines health literacy as a 'constellation of skills, including the ability to perform basic reading and numeric skills required to function in the healthcare environment'. ${ }^{13}$ Conceptually, health literacy has moved from functional skills in the medical setting to being a multidimensional concept that involves more advanced skills. Nutbeam ${ }^{14}$, for example, proposes a three-tiered concept of health literacy distinguishing between functional health literacy, interactive health literacy and critical health literacy. Schulz and Nakamoto stress the importance of knowledge as part of health literacy. In addition to basic reading and numeracy skills, their multidimensional concept of health literacy comprises declarative knowledge (factual knowledge related to health issues to be able to learn how to approach a health condition), procedural knowledge ('know-how' to apply factual knowledge and use health information in a specific context) and judgement skills (the ability to judge on the basis of factual knowledge necessary to deal with novel situations). ${ }^{11}$ In the context of vaccination, declarative knowledge includes, for instance, knowledge about infectious diseases or about the availability of vaccines. On the other hand, procedural knowledge entails knowing how and when to get vaccinated against infectious diseases.

Similar to health literacy, psychological empowerment is a characteristic of the individual, ${ }^{15}$ which manifests in four different dimensions: meaningfulness, competence, impact and self-determination. ${ }^{16}$ The multidimensional concept has its origins in the workplace setting where it has been studied in relation to job performance and management qualities. ${ }^{17}$ Transferred to the context of vaccination, meaningfulness refers to the degree to which an individual thinks that vaccination is an important means to remain healthy. Competence refers to the degree to which an individual feels able to get vaccinated. As such, competence is related to self-efficacy. ${ }^{7}{ }^{18}$ Impact refers to the degree to which an individual feels that being vaccinated has a positive impact on his health. In this respect, impact is closely related to feelings of internal control. ${ }^{19}$ Finally, self-determination refers to the degree to which individuals think that being vaccinated is determined by themselves. This dimension is also termed as locus of causality or perceived autonomy, and it is central to self-determination theory. ${ }^{20}$

In contrast to the assumption that health literacy empowers people to engage in health-related behaviour, ${ }^{21}$ Schulz and Nakamoto ${ }^{22}$ argue that higher levels of health literacy are not necessarily associated with empowerment. Instead, the authors separate both concepts and consider literacy and psychological empowerment as independent yet equally important determinants of health-related behaviour and outcomes. 
Both, health literacy and psychological empowerment, are related to information search behaviour, which entails "... active efforts to obtain specific information in response to a relevant event". ${ }^{23}$ Individuals who have the knowledge and skills to navigate the health system and are empowered to do so will search for information and recommendations on the topic of vaccination. The search for information, in turn, will increase their knowledge of vaccination resulting in a reciprocal relationship between information search behaviour and health literacy. However, information search behaviour is also linked to perceived knowledge, which is the extent to which individuals judge themselves as knowledgeable about health issues independently from their actual knowledge. Previous studies showed that increased levels of perceived knowledge are associated with decreased levels of information search. ${ }^{24}$ Therefore, individuals who think that they are knowledgeable about vaccinations and how to get vaccinated do not feel the need to actively search for information on the topic. This is especially critical when the perception of knowledge deviates from actual knowledge. The described relationships have been translated in an Extended Health Empowerment Model as shown in figure 1.

The model also includes confounding variables that are deemed to have an impact on health behaviour. These variables comprise intrapersonal and interpersonal factors. In the context of vaccination, intrapersonal factors are, for example, the perceived risk of getting infected by a disease compared with the perceived risk of the vaccination itself. Furthermore, individuals' ideologies, that is their attitude towards medicine and science, plays a role in their decision whether to receive a vaccination or not. ${ }^{25}$ Among interpersonal factors, behaviour of the peer reference group impacts own behaviour in that perceptions of social pressure may cause individuals to do what their peers do. This applies to both engaging in health behaviour such as getting vaccinated as well as avoiding the behaviour. ${ }^{26}$ Eventually, the relationship with healthcare providers and trust in these providers and the healthcare system contribute to individuals' decisions to follow recommended vaccination calls. $^{25}$

\section{Study objectives}

Although the COPH has a detailed record of the vaccination coverage among adolescents in Switzerland, little is known about the factors that determine parents' decisions to get their children vaccinated. Based on the Extended Health Empowerment Model by Schulz and Nakamoto, ${ }^{22}$ the present study aims at surveying parents of adolescents in Ticino to get insights into the role of health literacy, health empowerment, information search behaviour and potential confounding variables that influence whether adolescents are not at all vaccinated,

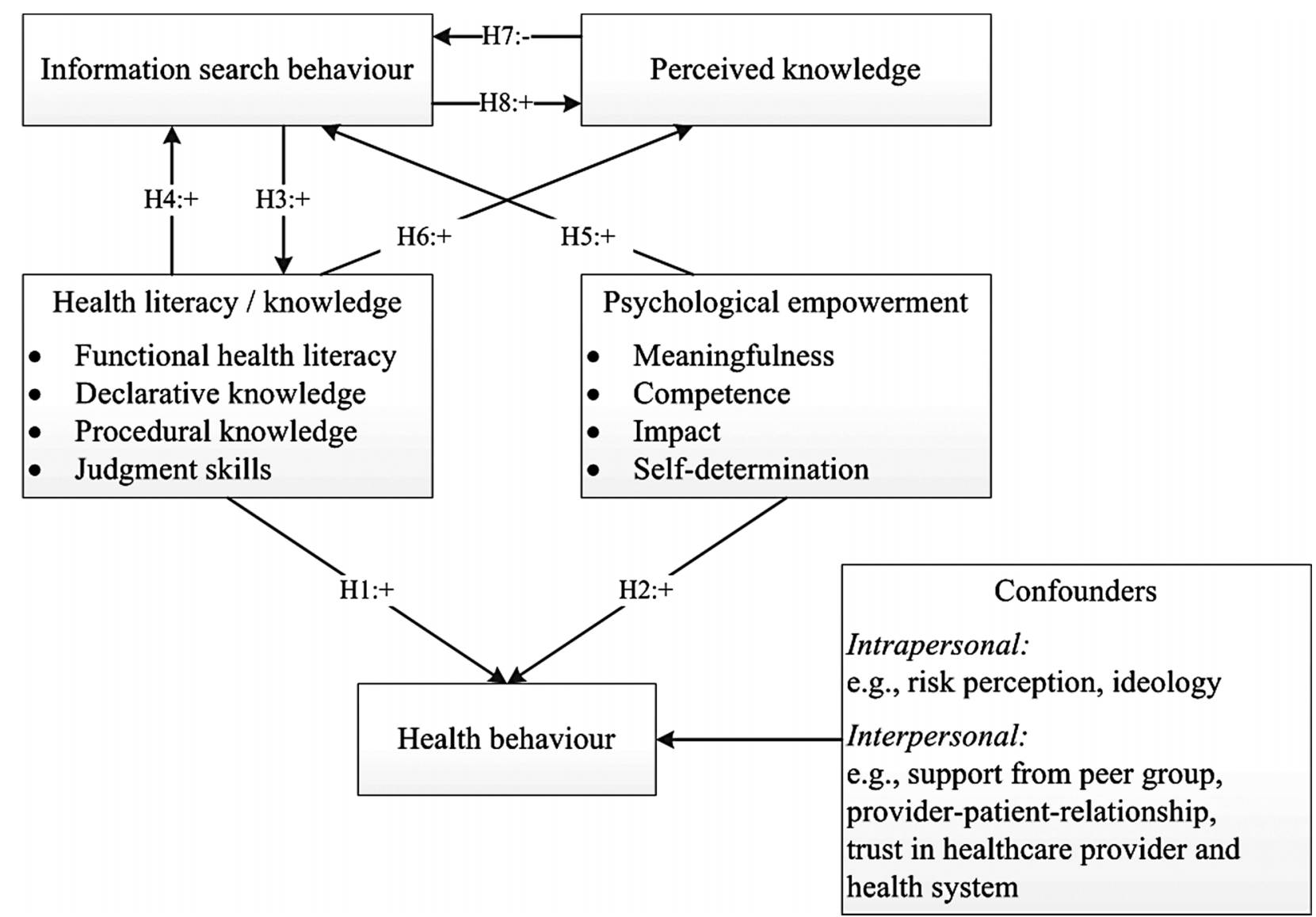

Figure 1 Extended Health Empowerment Model adapted from Schulz and Nakamoto. ${ }^{22}$ 
undervaccinated or fully covered. For this purpose, survey data will be matched with vaccination coverage data collected from the COPH in Ticino to test the following set of hypotheses:

H1: The more knowledgeable parents are about infectious diseases and vaccinations, the more likely it is that their child is fully vaccinated.

H2: The more empowered parents are regarding the topic of vaccinations, the more likely it is that their child is fully vaccinated.

H2a: The more parents consider that vaccination against infectious diseases is important, the more likely it is that their child is fully vaccinated.

H2b: The more parents feel competent in their ability to get their child vaccinated, the more likely it is that their child is fully vaccinated.

H2c: The more parents think that vaccination has a positive impact on their child's health, the more likely it is that their child is fully vaccinated.

H2d: The more parents feel autonomous in decisions regarding the vaccinations of their child, the more likely it is that their child is fully vaccinated.

H3: The more parents search for information on the topic of vaccination, the more knowledgeable they are about infectious diseases and vaccinations.

H4: The more knowledgeable parents are about information sources, the more they search for information on the topic of infectious diseases and vaccinations.

H5: The more empowered parents are regarding the topic of vaccinations, the more they search for information on the topic.

H6: The more knowledgeable parents are about infectious diseases and vaccinations, the more they perceive themselves as knowledgeable about the topic.

H7: The more knowledgeable parents perceive themselves about infectious diseases and vaccinations, the less they search for information on the topic.

H8: The more parents search for information about infectious diseases and vaccinations, the more they perceive themselves as knowledgeable on the topic.

\section{DESIGN AND METHODS}

\section{Study population}

Vaccination coverage data will be collected from all adolescents attending the third year of public and private ${ }^{1}$ middle schools in the Canton of Ticino. During the school year 2011/2012, 3047 adolescents were registered between the age of 14 and 16 in the second year. ${ }^{27}$ All parents of these adolescents will be invited to participate in the survey to get insights into the factors that contribute to their decisions and actions to get their children vaccinated or not. Since participation in the survey is not compulsory, we do not expect a response rate equal

\footnotetext{
${ }^{1}$ Only private schools with degrees accepted by the Canton of Ticino are considered ('scuole private parificate').
}

to the amount of vaccination coverage data. However, an a priori sample size calculation showed that a minimum number of 166 survey responses would be sufficient to test the proposed model in figure 1, using structural equation modelling (SEM) techniques. We followed a limited information approach to obtain a rough approximation of the minimum sample size. This technique uses traditional power analysis software to gain a sense of sample size demands. ${ }^{28}$ More specifically, a power analysis was conducted for a path coefficient for a predictor that accounts for at least $5 \%$ unique variance in the outcome. As can be seen in the model in figure 1, the maximum number of latent predictors for a linear equation is 10. Assuming at least three manifest indicators per latent predictor, a squared multiple correlation of 0.20 , a $0.05 \alpha$ level, and a two-tailed test, a sample size of 166 would be needed to achieve a power of 0.95 , which would be satisfactory for the proposed analyses. Given that the survey will be conducted in Italian, only parents fluent in this language will be invited to participate. Furthermore, the survey will address the parent who usually takes care of the child's health and plays a central role in decisions concerning preventive behaviour. Experiences of healthcare providers show that this parent is usually the mother. ${ }^{29}$

\section{Data collection}

An information letter will be sent, via regular mail, by COPH to all households with adolescents attending the third year of middle school in Ticino. The letter will advise parents to give the vaccination card to their children, in order to bring it with them to school. At the same time, all households will receive an invitation letter to take part in the survey. Parents who agree to participate in the survey will be asked to fill out a response card in which they will give their consent and provide their preferred contact details (regular mail address, e-mail address or telephone number). The adolescent will bring both the vaccination and the response card to school and school doctors will indicate on the response card of those adolescents whose parents have agreed to participate in the survey whether the adolescent is fully vaccinated, undervaccinated or not at all vaccinated against MMR. The response card will then be forwarded to the Institute of Communication and Health and parents will receive a standardised self-administered questionnaire via regular mail or e-mail. For those parents who opted for a telephone interview a Computer Assisted Telephone Interview will be conducted. Once data collection is over, the answers of parents will be matched with the vaccination coverage data of their children.

\section{Measurements}

\section{Vaccination coverage against MMR}

Vaccination coverage against MMR is an objective measure of past health behaviour collected by school doctors from adolescents' vaccination cards. It serves as an outcome measure with three values: fully vaccinated 
against measles (two doses of vaccine), partially vaccinated (one dose of vaccine) and not at all vaccinated.

Data about parents' health literacy, empowerment, information search behaviour and other relevant factors will be collected by means of a standardised questionnaire including detailed measures covering all the concepts included in the Extended Health Empowerment Model presented above.

\section{Functional health literacy}

Functional health literacy will be assessed by means of three screening questions developed and validated by Chew and colleagues. ${ }^{30} 31$ The questions are based on self-report, and an example would be: "How often do you have difficulties filling out medical forms by yourself", with response options ranging from always to never on a five-point Likert scale.

\section{Objective and perceived knowledge}

Objective and perceived knowledge will be assessed with nine true/false statements about childhood vaccination. For instance, parents will be required to decide whether the statements "Measles can be prevented by vaccination in childhood" (declarative knowledge) or "In order to get my child vaccinated against measles I have to go to a hospital" (procedural knowledge) are true or false. All the statements will be based on previous studies assessing parents' knowledge about childhood vaccination. $^{32}$ Additionally, in order to assess the respondents' confidence that the given answer is accurate (perceived knowledge), immediately after every statement they will be asked "How certain are you that your answer is correct?", with response options ranging from not at all certain to very certain on a five-point Likert scale. In addition, two questions will be included to measure respondents' perceived general knowledge on the topic of measles and vaccination, again with response options ranging from not at all certain to very certain on a fivepoint Likert scale.

\section{Psychological empowerment}

Psychological empowerment will be assessed by means of 12 items, with three items covering each of the fourdimensions adapted from Spreitzer: meaningfulness (eg, "The vaccination of my children is very important to me"), competence (eg, "I am confident about my ability to make decisions regarding the vaccination of my children"), impact (eg, "I have a great deal of control over the vaccination of my children) and selfdetermination (eg, "I can decide on my own how to proceed with the vaccination of my children"). ${ }^{17}$ Respondents will be asked to answer on a seven-point Likert scale ranging from strongly disagree to strongly agree.

\section{Information search behaviour}

Information search behaviour will be measured with two questions that account for respondents' experiences with the search for health information. The questions consider general health information seeking (eg, "Did you ever seek for health information from any source?") and specific health information seeking in the field of vaccination (eg, "Did you ever seek for information about child vaccination from any source?"). The measures used are adaptations from questions already established in the literature. ${ }^{34}$

\section{Confounders}

Detailed data will be collected about intrapersonal and interpersonal factors that could play a role in explaining parents' decision to vaccinate their children beyond the concepts mentioned before. Confounders include validated measures for risk perception, ${ }^{35}$ health beliefs, ${ }^{36}$ social support ${ }^{37}$ and provider-patient relationship ${ }^{38}$ that have been adapted to the context of vaccination and the Swiss healthcare system. In particular, participants will be asked about the perceived risk for their child of getting an infectious disease (eg, "How likely is it that your child will suffer from measles during the course of his life?"), about the perceived risk for their child of experiencing side-effects of vaccination (eg, "How likely is it that your child will get fever after his measles vaccination?"), about their beliefs regarding vaccination (eg, "Vaccination about measles is not necessary because it is better when my child develops a natural immunity"), about the perceived support and influence of the peer group (eg, "There is too much social pressure to vaccinate children"), about their relationship with their healthcare providers (eg, "We asked our doctor to explain us why our child should be vaccinated against measles") and, finally, about their trust in the healthcare provider (eg, "I usually follow my doctor's recommendations regarding vaccinations") and in the healthcare system (eg, "I usually follow cantonal recommendations regarding vaccination"). All response options will be presented together with a seven-point Likert scale ranging from one strongly disagree to seven strongly agree.

\section{Sociodemographic characteristics}

Detailed data will be collected about the sociodemographic background of the respondents. Of particular interest will be the household structure (ie, marital status of the parents and number of older and younger siblings), origins and the educational attainment of both parents.

\section{Data analysis}

The collected data will be analysed quantitatively using statistical software packages. Prior to main analyses, data will be assessed for univariate and multivariate outliers, non-normality and missing data. Confirmatory factor analysis will be used to evaluate the validity and reliability of the measures from the survey. SEM techniques will be applied to test the model presented in figure 1. Since the outcome variable is ordinal (not at all vaccinated, under-vaccinated, fully vaccinated), logistic regressions will allow one to determine the likelihood that 
adolescents fall in one of the three groups based on the predictors identified in the model.

\section{Ethics and dissemination}

The study has obtained ethical approval by the Ethical Committee of Canton Ticino (Switzerland) on 25 June 2012 (Rif. CE 2576) inasmuch it neither modifies physical or psychological conditions of the adolescents nor of their parents. Moreover, participation in the survey and consent to match survey answers and data about adolescents' vaccination coverage is voluntary. All data will be analysed in anonymous form and any personal details such as name or address of the parents will be deleted as soon as all survey data are collected and matched to vaccination coverage data of their children. For the purpose of data analysis, each adolescent will be transformed into a case and an identification number (eg, 001, 002, etc.) will be attributed.

The results will be disseminated via peer-reviewed scientific journals and conference presentations. The main findings will be made available to the general public via press release and other dedicated public events organised in collaboration with the COPH in Ticino.

\section{DISCUSSION}

\section{Strengths and limitations}

The main strength of this study resides in the fact that it is the first to test the Extended Health Empowerment Model as a whole. Indeed, the questionnaire developed for this study includes measures for all the components of the model but for judgment skills since to date no valid tool to measure individuals' decision-making in the context of childhood vaccination exists. We think that more research is needed to operationalise the concept of judgment skills-especially in the context of (childhood) vaccination-before it can be used in comprehensive surveys like this one. A second important strength is the fact that survey data will be matched with actual data about adolescents' measles vaccination coverage, which is systematically collected by well-instructed school doctors. Most of the existing studies ${ }^{32} 39$ rely on self-report data which could be unreliable, inasmuch we assume that parents are not always aware of the vaccination status of their children. ${ }^{40}$ Another strength is the fact that all families with a child attending the third year of middle school will be invited to take part in the study. Given that this is the prefinal year of compulsory education in Switzerland, it will provide us with access to a complete section of the Ticino population, providing the opportunity to gather data from a representative sample. Additionally, adolescents in their third year of middle school will still be within their compulsory education during 2014, which gives the possibility to plan a follow-up study after the 2013 campaign.

However, the study also has some limitations. A first potential limitation of the proposed study could be the risk of a low response rate. Indeed, although power calculation showed that a sample size of 166 would be sufficient for statistical purposes, a bigger sample size is needed in order to obtain representative results. For this reason, great effort will be put in systematically trying to increase the response rate by contacting all participants up to three times using the preferred form of contact (post, e-mail and phone). A second potential weakness of the study resides in the fact that measles vaccination rates in Ticino are relatively high and, therefore, there is a risk of low variance in the outcome measure. A possible way to address this issue would be to add a question about parents' general attitude towards childhood vaccination, which we expect to have more variance inasmuch not all parents who decide to vaccinate their children against measles are in favour of other vaccinations. This general attitude question could serve as an outcome measure related to more general questions addressing the aforementioned predictors of health behaviour. Moreover, the efforts described above to boost the response rate will increase the likelihood of having a higher variance in the outcome variable. A third potential weakness of the study is the risk of a self-selection bias (ie, the risk that only parents strongly in favour or strongly against vaccination decide to participate in the survey). However, the abovementioned question about general attitude towards vaccination, in addition to a comparison of vaccination rates in the survey sample with those of the whole population, will allow us to detect such a bias and to take it into account during the discussion of our findings. A fourth and last potential weakness of the study resides in the use of three different data collection methods (ie, selfadministered postal questionnaire, online questionnaire and computer-assisted telephone interview). A possible way to address this limitation is to add the data collection method as a confounder in the model and account for it in the data analysis.

\section{Implications}

In addition to the provision of new evidence for the validity of the Health Empowerment Model in a field different from those in which it has already been tested (eg chronic low-back pain or fibromyalgia), ${ }^{41}{ }^{42}$ this study will take into account further predictors of health behaviour by testing an extended model which includes information search behaviour and perceived health knowledge. As such, the results of this study will allow drawing more comprehensive conclusions about the factors that play a role in parents' decision regarding the vaccination of their children. At the same time, the study will provide useful insights on which are the main issues to be addressed when dealing with parents and vaccination-related concerns.

Contributors All authors took part in the design and the development of the study. ND, ALC and PJS took part in the development of the survey while $D R$ and $A G$ took part in the planning of the collection of the adolescents' vaccination coverage data. ND and ALC contributed to the writing of the final 
manuscript. ND revised the manuscript with input and advice from all authors.

\section{Competing interests None.}

Funding This research received no specific grant from any funding agency in the public, commercial or not-for-profit sector.

Provenance and peer review Not commissioned; externally peer reviewed.

\section{REFERENCES}

1. Centers for Disease Control and Prevention, CDC. Measles - United States, January-May, 2011. MMWR 2011;60:666-8.

2. World Health Organization, WHO. Measles vaccines: WHO position paper. Wkly Epidemiol Rec 2009;84:349-60.

3. Lang P. Vaccination status of children in Switzerland [Unpublished doctoral dissertation]. Switzerland, University of Basel, 2007.

4. FOPH, Federal Office of Public Health. Strategia nazionale per l'eliminazione del morbillo 2011-2015. Versione breve. (National strategy for elimination of measles 2011-2015. Short version). Bern: Federal Office of Public Health, 2012.

5. FOPH, Federal Office of Public Health. Masern (Measles). In Health in Switzerland. Federal Office of Public Health 2012. Retrieved 1 September 2012, from http://www.bag.admin.ch/themen/medizin/00682 00684/01087/index.html?lang=de (accessed 1 September 2012).

6. Strecher VJ, Rosenstock IM. The health belief model. In: Baum A Newman S, Weinman J, et al., eds. Cambridge handbook of psychology, health, and medicine. Cambridge: Cambridge University Press, 1997:113-16.

7. Bandura A. Social foundations of thought and action: a social cognitive theory. EnglewoodCliffs, NJ: Prentice-Hall, 1986.

8. Bandura A. Social cognitive theory. In Vasta R ed. Annals of child development. Vol. 6. Six theories of child development. Greenwich, CT: JAI Press, 1989:1-60.

9. Ajzen I. From intentions to actions: a theory of planned behaviour. In: Kuhl J, Beckman J, eds. Action-control: from cognition to behaviour. Heidelberg, Germany: Springer, 1985:11-39.

10. Greenhalgh T. Chronic illness: beyond the expert patient. BMJ 2009;338:b49.

11. Schulz PJ, Nakamoto K. Emerging themes in health literacy. Stud Commun Sci 2005;5:1-10.

12. 'literacy'. Oxford Dictionaries. April 2010. Oxford University Press. Retrieved 1st September 2012, http://oxforddictionaries.com/ definition/literacy?q=literacy

13. Ad Hoc Committee on Heath Literacy for the American Council on Scientific Affairs, American Medical Association. Health literacy: report of the council on scientific affairs. JAMA 1999;281:552-7.

14. Nutbeam D. Health literacy as a public health goal: a challenge for contemporary health education and communication strategies into the 21st century. Health Promot Int 2000;15:259-67.

15. Rissel C. Empowerment: the holy grail of health promotion? Health Promot Int 1994:9:39-47.

16. Thomas KW, Velthouse BA. Cognitive elements of empowerment: an 'interpretive' model of intrinsic task motivation. Acad Manag Rev 1990;15:666-81.

17. Spreitzer GM. Psychological empowerment in the workplace: dimensions, measurement, and validation. Acad Manag $J$ 1995;38:1442-65.

18. Bandura A. Self-efficacy: toward a unifying theory of behavioural change. Psychol Rev 1977;84:191-215.

19. Rotter JB. Generalized expectancies for internal versus external control of reinforcement. Psychol Monogr 1996;80:1-28.

20. Deci EL, Ryan RM. Intrinsic motivation and self-determination in human behaviour. New York: Plenum Publishing Corp, 1985.

21. Nutbeam D. Health promotion glossary. Health Promot Int 1998:13:349-64.
22. Schulz PJ, Nakamoto K. Health literacy and patient empowerment in health communication: the importance of separating conjoined twins. Patient Educ Couns Published online first: 11 October 2012. doi: 10.1016/j.pec.2012.09.006

23. Niederdeppe J, Hornik RC, Kelly BJ, et al. Examining the dimensions of cancer-related information seeking and scanning behaviour. Health Commun 2007;22:153-67.

24. Radecki CM, Jaccard J. Perceptions of knowledge, actual knowledge, and information search behaviour. J Exp Soc Psychol 1995;31:107-38.

25. Smailbegovic MS, Laing GJ, Bedford $\mathrm{H}$. Why do parents decide against immunization? The effect of health beliefs and health professionals. Child Care Health Dev 2003;29:303-11.

26. Sturm LA, Mays RM, Zimet GD. Parental beliefs and decision making about child and adolescent immunization: from polio to sexually transmitted infections. J Dev Behav Pediatr 2005;26:441-52.

27. Ufficio dell'Insegnamento Medio. Statistica scuola media di fine anno 2010-11 (Middle school statistics 2010-11). In Ufficio dell'insegnamento medio 2012. Retrieved 1st September 2012, from http://www4.ti.ch/decs/ds/uim/ufficio.

28. Jaccard J, Wan CK. LISREL approaches to interaction effects in multiple regression. Thousand Oaks, CA, London, UK, New Delhi, India: SAGE Publications, Inc., 1996

29. Dannetun E, Tegnell A, Hermansson G, et al. Parents' reported reasons for avoiding MMR vaccination: a telephone survey. Scand $J$ Prim Health Care 2005;23:149-53.

30. Chew LD, Bradley KA, Boyko EJ. Brief questions to identify patients with inadequate health literacy. Fam Med 2004;36:588-94.

31. Chew L, Griffin J, Partin M, et al. Validation of screening questions for limited health literacy in a large VA outpatient population. J Gen Int Med 2008;23:561-6.

32. Borràs $\mathrm{E}$, Dominguez $\mathrm{A}$, Fuentes $\mathrm{M}$, et al. Parental knowledge of pediatric vaccination. BMC Public Health 2009;9:154-60.

33. Freeman VA, Freed GL. Parental knowledge, attitudes, and demand regarding a vaccine to prevent varicella. Am J Prev Med 1999;17:153-5.

34. Anker AE, Reinhart AM, Feeley TH. Health information seeking: a review of measures and methods. Patient Educ Couns 2011;82:346-54.

35. Rimal RN, Real K. Perceived risk and efficacy beliefs as motivators of change. Use of the Risk Perception Attitude (RPA) framework to understand health behaviours. Hum Commun Res 2003;29:370-99.

36. Champion VL, Skinner CS. The health belief model. In: Glanz K, Rimer BK, Viswanath K, eds. Health behaviour and health education; theory, research, and practice. San Francisco, CA Jossey Bass, 2008:45-65.

37. Zimet GD, Dahlem NW, Zimet SG, et al. The multidimensional scale of perceived social support. J Pers Assess 1998;52:30-41.

38. Thom DH, RibisI KM, Stewart AL, et al. Further validation and reliability testing of the trust in physician scale. Med Care 1999;37:510-17.

39. Angelillo IF, Ricciardi G, Rossi $P$, et al. Mothers and vaccination: knowledge, attitudes, and behaviour in Italy. Bull World Health Organ 1999;77:224-9.

40. Morse D, O'Shea M, Hamilton G, et al. Outbreak of measles in a teenage school population: the need to immunize susceptible adolescents. Epidemiol Infect 1994:113:355-65.

41. Camerini AL, Maino P, Nakamoto K, et al. Predictors of Psychological Empowerment in Patients with Chronic Low Back Pain: A Cross-Sectional Study in the French and Italian Parts of Switzerland. Under review.

42. Camerini L, Schulz PJ, Nakamoto K. Differential effects of health knowledge and health empowerment over patients' self-management and health outcomes: a cross-sectional evaluation. Patient Educ Couns Published online first: 4 September 2012. doi: 10.1016/j.pec. 2012.08.005 